such as sociology, psychology, and biomathematics have been added.

In anatomy preclinical students have to attend courses on histology $(52 \mathrm{~h})$, dissection of the body $(104 \mathrm{~h})$, and dissection of the brain $(8 \mathrm{~h})$, giving a total of $164 \mathrm{~h}$ of practical work. They can attend lectures on macroscopic anatomy $(65 \mathrm{~h})$, histology (65 h), macroanatomy $(52 \mathrm{~h})$, and embryology $(26 \mathrm{~h})$, totalling $208 \mathrm{~h}$. There is thus a potential total of $372 \mathrm{~h}$ of anatomy teaching, but for the past two years a sharp reduction in lecture attendance has been noted as local university examinations have been abolished and by this any feed-back between teacher and student; only written examinations conducted by a central examination board on the basis of multiple-choice questions can be taken. This type of question is highly unsuitable for a subject like anatomy, makes it unnecessary for a student to visualise body relations and to gain tactile experience or convey a spatial knowledge of the human body to an examiner.

The action of the EEC in allowing free exchange of doctors forces every national health authority to compare and evaluate the relative standards of medical education of member countries. I wonder which body or bodies are dealing with this real and very urgent problem. What is the educational background of a medical doctor in each of the EEC countries and is the training sufficient both in quality and quantity?

Paul Glees

Institut für Histologie und experimentelle Neuroanatomie, University of Göttingen

\section{Administration of diazoxide}

SIR,-The article by Dr J C Petrie on the treatment of hypertension (7 August, p 359) recommends that intravenous diazoxide should be given in a dose of $300 \mathrm{mg}$ over $10 \mathrm{~s}$. It is not generally recognised that this dose may be halved so that $150 \mathrm{mg}$ is given intravenously over $5 \mathrm{~s}$, thus producing a less dramatic fall in blood pressure. If the reduction in blood pressure is not of sufficient magnitude a further $150 \mathrm{mg}$ may be infused over $5 \mathrm{~s}$. The above method of giving intravenous diazoxide has the advantage of allowing a rough titration of the reduction in blood pressure.

R A SLOANE

Cairns,
Queensland, Australia

\section{A further endoscopy problem solved?}

SIR,-Mr J S Martin's letter (16 October, p 946) provides a reminder that a syndrome of temporomandibular symptoms may follow peroral endoscopy and other oral surgery. Owing to the prolonged depression of the mandible into an unusual phase of opening there is a tendency, on release, to a backward displacement of the meniscus in the temporomandibular joint if any slackness is present. Unless corrected this will affect the first phase of opening for normal use-speaking and chewing - and of the second phase-opening to accept a spoonful of food. This causes a wide range of symptoms varying from an overt click with or without trismus or pain to simple, often obscure, tensions in the muscles of mastication, of facial expression, and of the phary:2x and to "earache," "toothache," and temporal headaches with wider repercussions and false inferences.

A simple, safe, and painless self-manipulation, specifically designed for the purpose, has cured hundreds of such cases in my experience in general practice over the past 20 years. Momentary distraction of the temperomandibular joint at the affected phase of movement using a suitable prop between the molars as a fulcrum for the lever of the mandible is all that is required. The patient bites on the prop, consisting of a wooden or plastic rod of suitable thickness (a pencil or toothbrush handle, for example) placed transversely between the front molars, and presses the point of the chin down into the cup formed between thumb and first finger of a clenched fist. He or she then gives a firm upward jab with the base of the palm of the other hand striking up under the first fist, which acts as a buffer. This is usually repeated some six times as a first treatment and generally gives immediate relief.

Any residual symptoms or recurrence can equally easily be self-treated at any time, even by the most nervous individuals.

Pinhoe, Exeter

JOHN B TRACEY

\section{Urinary amyloid fibrils in the absence of} amyloidosis

SIR,-The detection of urinary amyloid fibrils by electron microscopy as a non-invasive diagnostic method for amyloidosis was put forward by $\mathrm{Mr} \mathbf{P}$ Nimoityn and others (31 July, p 284), who confirmed data reported by Derosena $e t a l^{1}$ and Neale et al. ${ }^{2}$ Continuing the discussion I would like to add a few points as a note of caution against the assumption that urinary amyloid can be taken as a reliable indicator for renal amyloidosis.

To begin with, Limas et $a l^{3}$ found amyloid in renal casts in 15 out of 35 patients with multiple myeloma. At necropsy, however, only eight of these 35 revealed amyloidosis, suggesting that amyloid may be present in casts from patients without concomitant amyloidosis. Our own studies ${ }^{4}$ have demonstrated that a substance having the essential properties of amyloid could be generated from the urine of a patient with Bence Jones proteinuria without amyloidosis at necropsy. This was simply done by incubating at $\mathrm{pH} 3.5$ and $37^{\circ} \mathrm{C}$ for over an hour without adding any enzyme. When, however, the purified Bence Jones protein (BJP) of this patient was treated identically the amyloid-like precipitate was found only after the addition of fresh urine. This experiment suggested to us the presence of amyloidogenic enzymic activity in the urine, particularly since the precipitate was composed of $\mathrm{N}$-terminal fragments of the intact BJP similar to those fragments present in amyloid fibrils in primary and myeloma-associated amyloidosis. ${ }^{5}$ In support of these findings is the report ${ }^{6}$ of a "proteolytic factor" cleaving BJP in two. Fibrillar amyloid-like precipitates may also be obtained by treating BJP with kidney extracts.? These findings are in line with the experiments of Glenner et al, 5 who showed for the first time the in-vitro formation of amyloid-like fibrils from some BJPs after digestion with pepsin.

Furthermore, when amyloid disease is experimentally induced in mice by casein injections a severe amyloidosis with renal involvement usually ensues. Yet in such mice amyloid could not be found in the urine, even though penetration of amyloid fibrils into the urinary space in two out of five animals was detected by electron microscopy. ${ }^{8}$ This observation confirms for the mouse model what Derosena et $a l^{1}$ had reported in man and indicates that in spite of the presence of amyloid in the renal urinary space the amount of amyloid excreted into the urine may be too small to detect, particularly when other insoluble substances are simultaneously present in high amounts.

In conclusion I suggest that urinary amyloid fibrils need not necessarily be derived from tissue amyloid but may also be formed by digestion of excreted light chains of immunoglobulins in patients without amyloidosis by an "amyloidogenic factor" in the urine.

\section{R P LINKE}

Chirurgische Klinik der Universität,

Institut für Experimentelle Chirurgie und Immunologie, ' Derosena, R, et al, New England fournal of Medicine,

Neale, T J, et al, New England fournal of Medicine, $1975,294,444$

Limas, C, et al, American fournal of Medicine, 1975.

54, 166.
- Linke, R , et al, fournal of Immunology, 1973, $11,10$. Glenner, G G, et al, Science, 1971, 174, 712. Biological Chemistry, McLaughlin, C L, Epstein, W V, et al, Laboratory and Clinical Medicine, 1974, 84, 107.

' Linke, R P, and Merker, H, Unpublished observations.

\section{Cramp in the elderly}

SIR,-Your expert, answering a question about night cramp in the elderly (9 October, p 861), mentions a number of drugs in addition to quinine sulphate.

Imipramine $10 \mathrm{mg}$ three or four times a day had been by far the best remedy I have tried since I had to give up daily quinine because of its ototoxicity about a year ago. I took it in the first place for nasal "catarrh," then realised that it, with quinine, had ended cramp completely, though with quinine only there was still a fair amount of cramp.

Could your expert please let me know if there are likely to be any long-term side effects ? I have experienced none in about 18 months except a welcome relief from catarrh as well as cramp. My age is 66 and I have suffered from severe cramp since adolescence.

H B LEE

Loughton, Essex

* *Our expert writes: "I was most interested to hear of your correspondent who can keep cramp at bay with $10 \mathrm{mg}$ of imipramine four times a day. Although there have been some cardiac deaths, usually associated with arrhythmias, in acute overdosage from imipramine there are, so far as I am aware, no records of chronic toxicity with this drug so far as the heart is concerned. The Committee on Safety of Medicines records show that from 1964 to 1971 approximately 1.4 million prescriptions were written each year for the drug. The number of cardiac deaths was in single figures and some of these may have been fortuitous. If your correspondent is fortunate enough to have found a drug which relieves cramp he may continue to take it with confidence. It is perhaps worth adding that most physicians now see little point in the administration of imipramine at frequent intervals. A single dose at night is often satisfactory. 